\title{
RNA + peptide editing in small soluble lipid binding proteins, a new theory for the origin of life on Earth's crust
}

Jean-François Picimbon ${ }^{1}$

${ }^{1}$ Qilu University of Technology School of Bioengineering

September 27, 2020

\begin{abstract}
"RNA + peptide editing are two successive independent mechanisms needed in order to make a panoply of new functional isoforms in a variety of binding protein families". I present the specificities of 'Chemosensory Proteins' CSPs in insects and argue about their potential role in life origins and evolution. In particular, I address the relatedness of the observed mutations in insect CSPs to the origin of life. I describe the observed mutations in these CSPs in several insect species are occuring via various mechanisms, RNA editing and/or during protein synthesis, and propose that such mechanism could have been important in the emergence and evolution of life on the Earth's crust.
\end{abstract}

\section{Hosted file}

PicimbonEcology\&Evolution-Sep2020.pdf available at https://authorea.com/users/362200/ articles/483428-rna-peptide-editing-in-small-soluble-lipid-binding-proteins-a-newtheory-for-the-origin-of-life-on-earth-s-crust

(1)

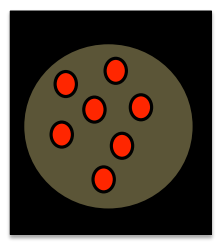

Meteorite crust

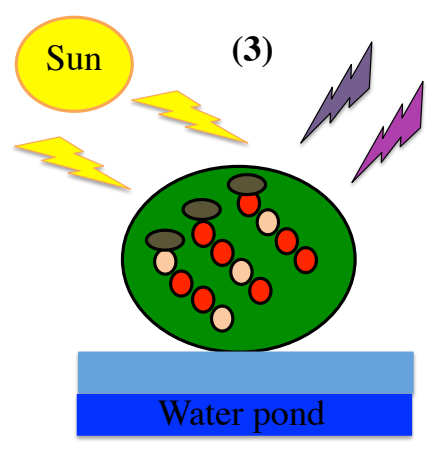

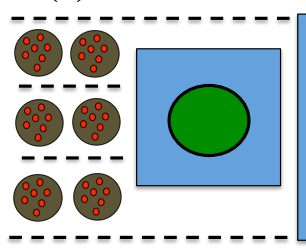

Rain of Stones

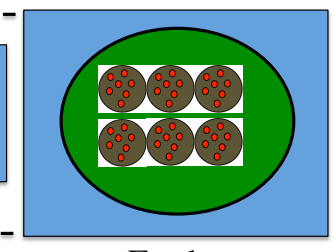

Earth crust

(4)

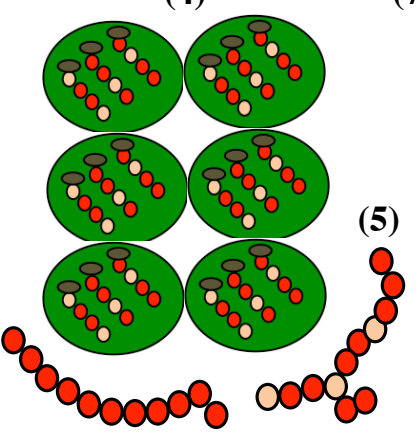

(2)

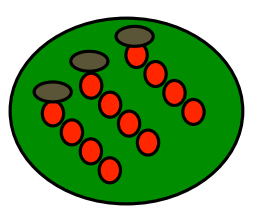

Lipid bilayer

(7)

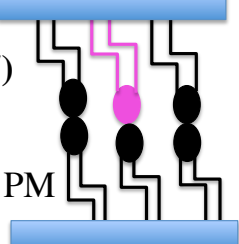

(5)

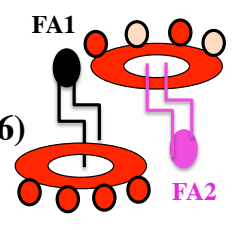



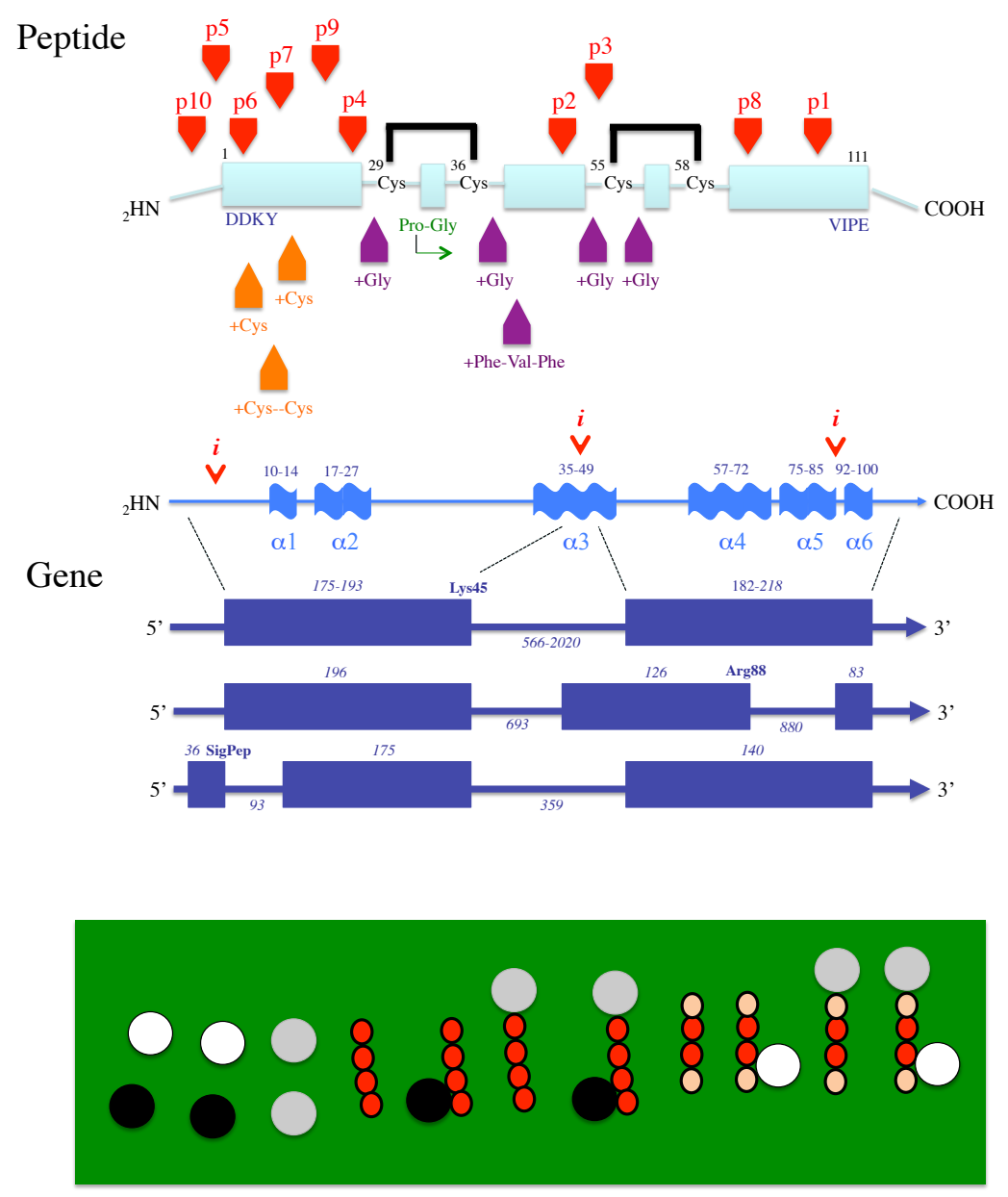

SPLICEOSOME-LIKE

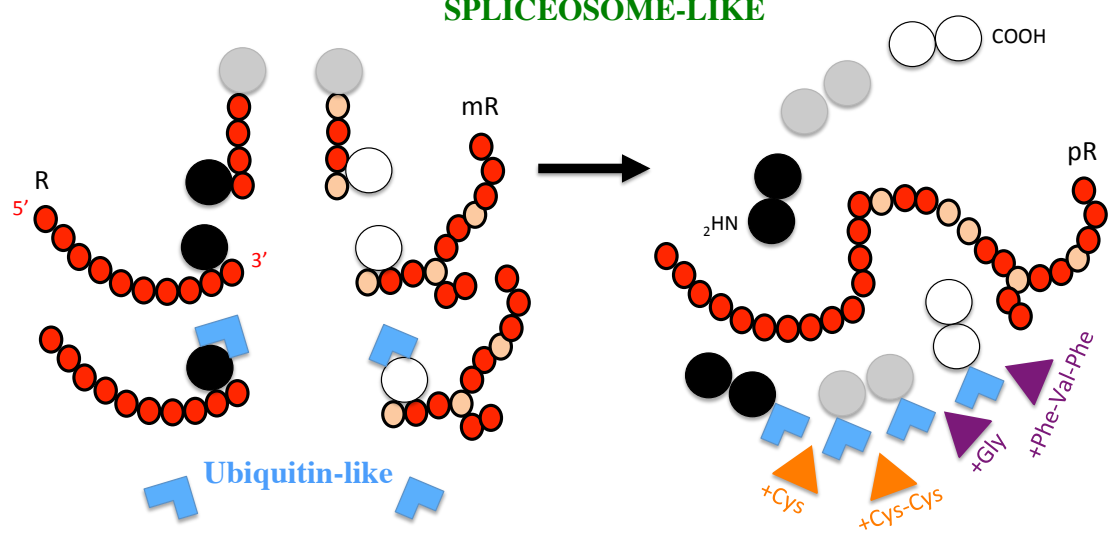



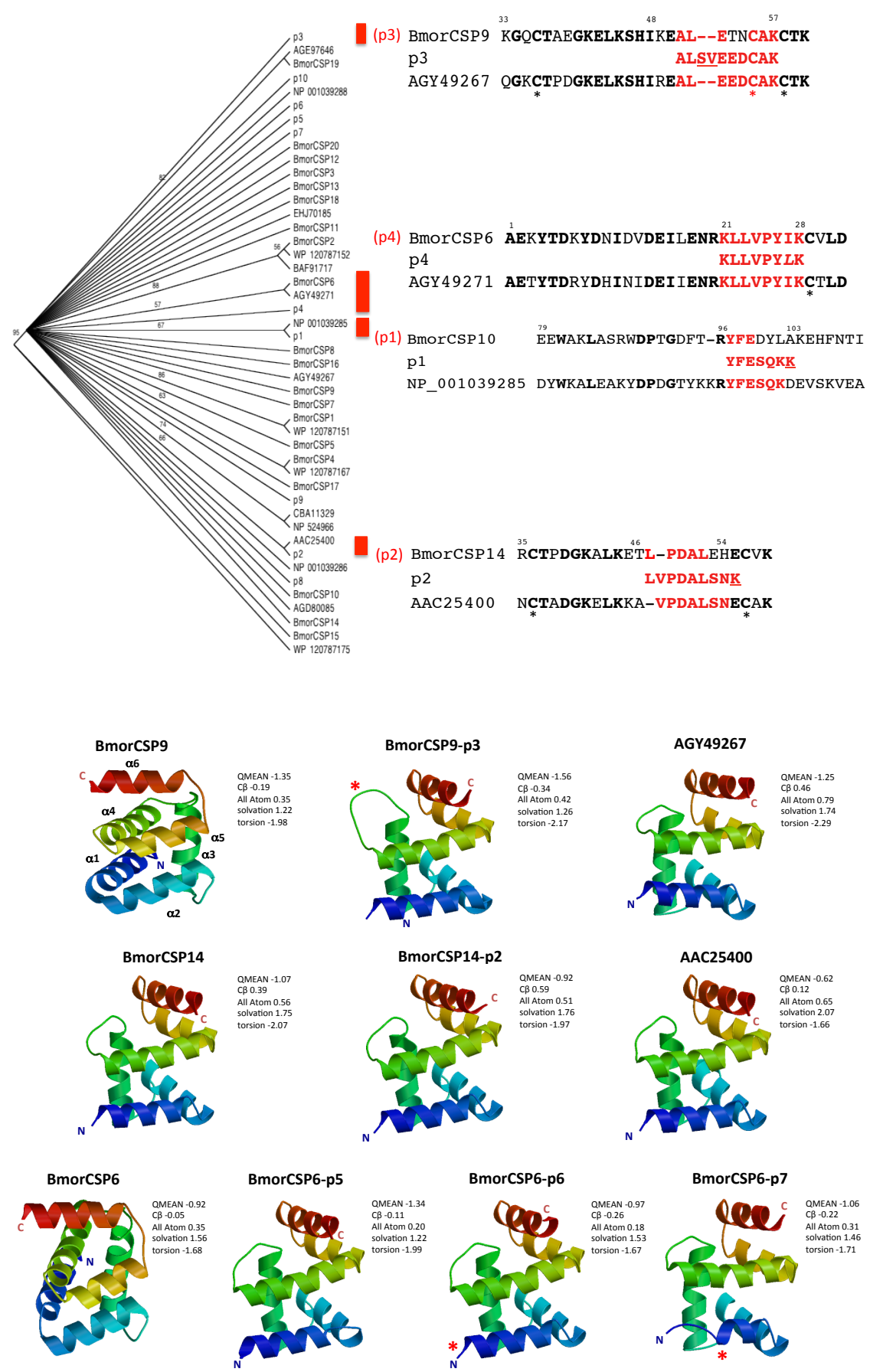
(3)

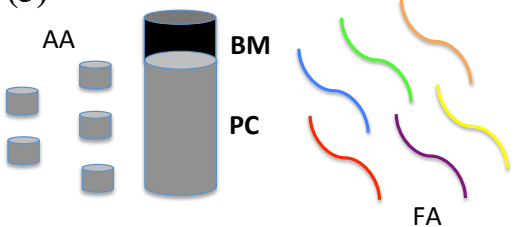

(2)

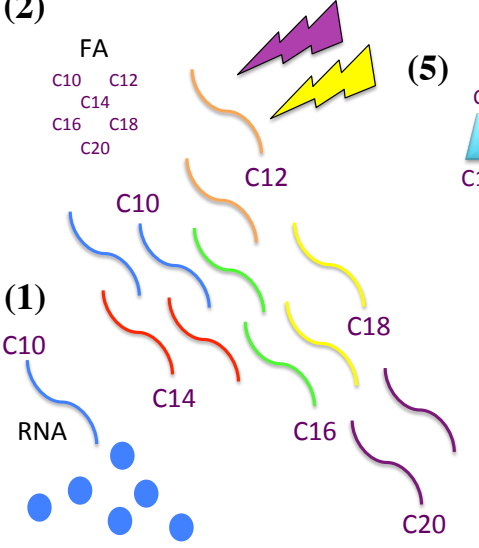

(4)

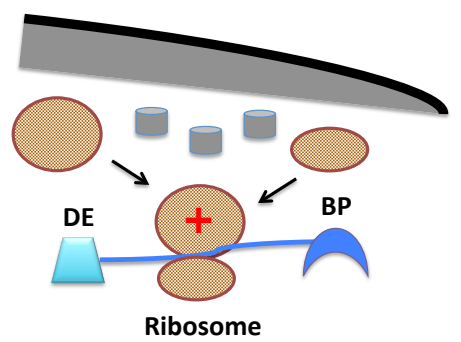

(6)
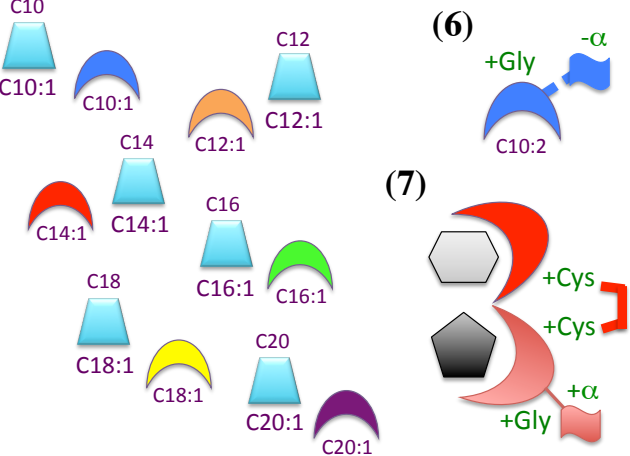